\title{
Factors Influencing Chinese Tourist to Select Bangkok, Thailand as A Travel Destination
}

\author{
Sumas Wongsunopparat ${ }^{1,2} \&$ Shen Jing ${ }^{3}$ \\ ${ }^{1}$ PHD, Johnson Graduate School of Management, Cornell University, United States of America \\ ${ }^{2}$ MBA, Tepper School of Business, Carnegie Mellon University, United States of America \\ ${ }^{3}$ Business Administration, Bangkok University, Bangkok, Thailand \\ Correspondence: Shen Jing, usiness Administration, Bangkok University, Bangkok, Thailand. E-mail: \\ shen.jing@bumail.net
}

Received: July 20, 2021

Accepted: September 15, 2021

Online Published: September 27, 2021

doi:10.5539/jms.v11n2p165

URL: https://doi.org/10.5539/jms.v11n2p165

\begin{abstract}
This study aims to investigate factors influencing the Bangkok-focused tourist destination selection in China. In addition, Kuala Lumpur and Tokyo, Japan were selected for comparison by assessing four destination attributes including culture, transportation, architecture, and food. In this study, we used a sample of 400 Chinese tourists who have traveled to Bangkok. The main research issue is to reveal the first- and second-order potential factors generating significant influences on Chinese tourists' choice of Bangkok as their destination. The aim of this study is to explore the structural relationships among the mentioned first-order and second-order latent variables, and their impact on the choice of tourist destinations in China. Due to the competitive nature of Chinese tourist destinations, we believe that there might be some potential factors that significantly affected their choice decision, therefore we applied the second-order Structural Equation Models (SEM) to capture these potentially unobservable factors. The result showed that our proposed model appeared to fit well: the RMSEA was 0.03 $(<0.06)$ and values of GFI, AGFI, NFI, TLI, and CFI were greater than 0.9 (most of them were even larger than 0.95). More importantly, Food (F), Emotional Factor (EF) representing food and cultural indulgence, and Physical Factor (PF) representing Architecture and Transportation facility of the destination showed significant impacts on tourist destination choice as their p-values were less than 0.05 . Hence, Thai food and anything that could maximize the emotional and functional values of Chinese tourists would make travel choices to become their travel destination. At the same time, it was aimed to provide some valuable suggestions for tourist cities currently under threat from COVID-19, to recover or better in the coming years, providing some evidence for future researchers to further explore this field.
\end{abstract}

Keywords: choice decision, Chinese tourist, tourist destination, culture, transportation, architecture, food, second-order SEM

\section{Introduction}

Currently, COVID-19 has been raging around the world, causing people unable to travel normally and economic depression, and bringing great impact and destruction to tourism. Many tourism-dominated cities and countries have suffered severe economic losses, leading to corporate bankruptcies and unemployment of workers. However, tourism has been widely regarded as one of the most important economic activities and a significant contribution to the development, well-being and prosperity of the national economy. After the end of the epidemic, how to actively restore tourism is particularly important.

Tourism is seen as the main driver of social and economic progress by providing employment opportunities, creating new businesses, developing infrastructure, and generating export revenue (the United Nations World Tourism Organization, 2017). Tourism is one of the most important elements of the global economy. More specifically, in 2017, tourism generated approximately $\$ 1.6$ trillion in revenue and became the third-largest export industry, followed by fuel and chemicals.

It is important that an individual view of images of a travel destination is a favorable travel choice. According to Augustyn and Ho (1998), they reported a better understanding of the motive and demands of tourists and accordingly tailored provisions to efficiently facilitate destination marketing. In addition, according to Hui et al. 
(2007), they noted that the growing importance of tourism to the national and global economy has led to growth in an exploratory study aimed to provide more valuable insights into factors (i.e., tourist satisfaction and motivation) influencing visitors to choose a specific travel destination. Since 2012, global tourism has maintained stable growth. For example, in terms of global tourist arrivals, the average annual increase rate was $3.6 \%$ in $2005-2012$.

The sharp and steady increase in tourism in Southeast Asia has sparked fierce competition amongst global destinations to appeal to tourists around the world, which has been studied in some previous papers. For example, according to the study conducted by Hui et al. (2007), they stressed that Bangkok, Kuala Lumpur, and Singapore competed to become the most popular tourism destinations. Furthermore, Crompton et al. (2001) concluded that the economic attributable influence on a travel destination was only associated with new revenue that the travel destination received from foreign tourists. Thus, foreign tourists had a greater influence than local tourists. It is important for Bangkok with a tourism development focus to understand tourists about Bangkok as destinations, which can provide analytical insights into how Bangkok can compete with travel destinations from neighboring countries. Additionally, Heung and Quf (2000) claimed that it is significant for tourism marketing to better understand tourists' preferences and travel-related behaviors, which can help destinations achieve market segmentation and carry out efficient promotion activities. It is also essential to provide services, products and infrastructure to meet tourist preferences since Southeast Asia has become one of the most popular tourist destinations around the world.

\section{Literature Review and Hypothesis Development}

\subsection{Literature Review}

Academia has conducted extensive and in-depth explorations of the current development status and stage characteristics of the tourism industry, market influential factors, development strategies and policy choices, destination market positioning, behavior and consumption characteristics, and cultural values.

Explore the relationship between tourist choice behavioral attributes and destination loyalty (Chen et al., 2001). Different cultural experiences, safety and convenient transportation, were significantly related to their destination loyalty. Chen et al. (2013), Lee (2015) and Zhang et al. (2018) also mentioned delicious food, local setting and entertainment were destination products, making a memorable experience and all affecting the choice of a tourist destination. Chandralal and Valenzuela (2015) also used novel experiences as variables in the study, including local hospitality, guides, affective emotions of tour operators, social interactions with people, the fulfillment of personal travel interests, and surprising experiences. Bonn et al. (2007) and Gelbman and Timothy (2011) also mentioned transportation facilities, as well as organizational and environmental services.

Mohaidin et al. (2017) found that environmental attitude, motivation, and word-of-mouth significantly influenced the tourists' intention to select sustainable tourism destinations, while destination image and perceived service quality did not have a significant influence in their study called 'Factors influencing the tourists' intention to select sustainable tourism destination: a case study of Penang, Malaysia'. In 2017, Mai Ngoc Khuong and Pham Anh Nguyen demonstrated that the impact of recreations and entertainments, natural environment, and cultural and historical attractions directly and indirectly on tourist destination satisfaction. Pantouvakis Angelos and Patsiouras Christos (2016) found that the main factors for tourists' destination choice were customs procedures, cultural and historical attractions, low crime rates, constant political environment, stability of currency and exchange rates, availability of nightlife activities and recreational facilities, overall value and cost levels and finally the availability of hotels. JAC Pallavicini (2017) reported in his study of Factors Influencing Tourism Destinations Attractiveness that a beautiful location with impressive hotels was important, but not enough to attract contemporary tourists by observing Malaga cases and a short analysis of other cities. Attractiveness meets tourist perceptions and expectations by creating adequate conditions to utilize the local resources of the destination. Leili Tapak, Hamed Abbasi and Hamid Mirhashemi (2019) studied the assessment of factors affecting tourism satisfaction using K-nearest neighborhood and random forest models and found that social behavior, municipal equipment and cost of services were the three top variables predicting tourist satisfaction. Considering the tourism capacity of the ancient city of Hamadan, policy-makers can use the results of planning for providing sustainable development and flourishing tourism in the city. L Tsourgiannis et al. (2015) identified major factors affecting Greek vacations in Greece. These factors included: (a) vacation activities (b) natural environment and entertainment (c) travel connections and (d) culture. These factors all affected the destination choice of tourists.

Currently, global tourism is being greatly affected by the outbreak of COVID-19. In the context of this era, the global tourism industry is being in a downturn (Jun et al., 2021). This study was based on the news broadcasted 
by multiple media outlets, and was supported by an overview of tourism marketing-related literature. The impact of COVID-19 on Chinese lifestyle choices, travel behaviors and tourism preferences were elaborated, and a series of measures for the tourism and hotel industry to deal with this impact was proposed. This article filled in the problems faced by the tourism industry after the COVID-19 outbreak and provided some effective strategies to help tourism practitioners and policymakers develop specific strategies. It has some practical significance for the future planning of global tourism. However, there is also Insufficiency, and do not mention how tourism has deepened the charm of attracting tourists after the epidemic.

Tourism scholars have also believed that resilience is essential to sustainable tourism. In this context, resilience reflects place-based information derived from a wide range of human-land interactions. For example, in 2011, rural communities in northeastern Japan had to recover from a 9.0-magnitude earthquake that triggered a tsunami and caused over 15,000 deaths (Kato, 2018). Such studies on tourism-related resilience after catastrophes have provided useful suggestions on industry recovery. The results have also focused on tourist behavior shortly after a disaster, which can inform longer-term behavioral patterns (Tsai et al., 2016).

Previous studies on this topic have mostly focused on a set of variables of interest for certain destination targets, and then tested each variable in their model separately to determine which variable significantly had a significant effect on the choice of the tourist destination. Consequently, the findings were very scattered based on the variables selected in the study. We believe that there might be some potential domains driving all of these significant findings in the previous literature. Therefore, we incorporate second-order latent factors, so-called emotional and physical factors, into our structural equation models to see if these common domains might be driving causes found by previous researchers in their studies.

\subsection{Theoretical Framework}

As mentioned above, we decided to apply a second-order structural equation model to estimate the relationship of all the first-order: C (Culture), A (Architecture), T (Transportation), F (Food); and second-order: EF (Emotional Factor), PF (Physical Factor) latent variables and their causal effects to have an overall impact on their tourist destination choice as shown in the following conceptual model.

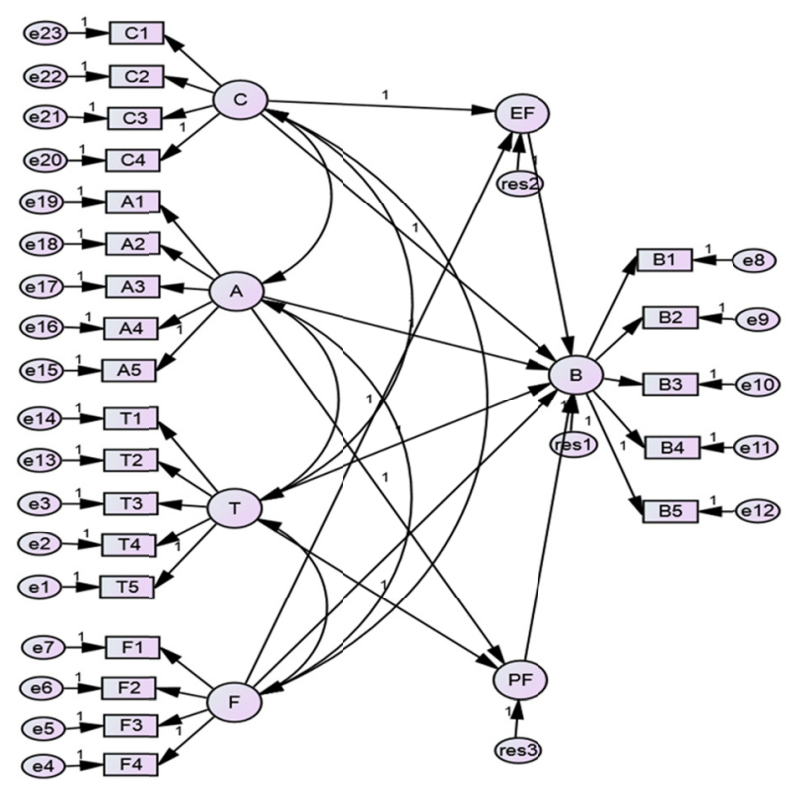

Figure 1. SEM model

Moreover, we also performed a comparative analysis using Multinomial Logistic Regression on the advantages of each preferred destination of Chinese tourists (Bangkok, Kuala Lumpur, Japan). We also studied the tourist profiles of each destination in the study to enable customer segmentation of each destination.

Thus, our study was conducted with the following hypotheses:

H1: Culture significantly affects choice for Chinese tourist destinations. 
$\mathrm{H} 2$ : Architecture remarkably influences the choice of Chinese tourist destinations.

H3: Transportation greatly affects choice for Chinese tourist destinations.

H4: Food largely influences the choice of Chinese tourist destinations.

H5: Emotional factor greatly impacts choice for Chinese tourist destinations.

H6: Physical factor significantly affects choice for Chinese tourist destinations.

\section{Research Methodology}

This study uses a quantitative approach to explore factors influencing Chinese tourists to select Bangkok, Thailand as a travel destination. Meanwhile, in this study, questionnaires were utilized to collect information and data in order to gather primary sources (Rowley, 2014). In terms of reliable secondary sources, online databases, relevant articles, and journals were included. To achieve the research objectives, the tool of quantitative research was adopted. Furthermore, the questionnaire was applied as a research instrument through relevant theories and agreed with the expertise. The data collected from the questionnaire was analyzed via Structural Equation Modeling (SEM) method.

Population data were collected from Chinese tourists (those living outside of the tourism destinations) who visited and experienced selected tourism destinations in our study including Bangkok, Kuala Lumpur, and Japan. A self-administered survey was employed in this study. The selected potential samplings were required. Participants were invited to complete the questionnaire online. A structured questionnaire was used to measure the culture, architecture, transportation, and food of the destination, as well as demographic and geographic background variables. The survey instrument was based on the 5-Likert scales. These studies collected random samplings data online of Chinese tourists from at least one of the selected destinations. A total of 400 surveys were obtained with no missing values. Therefore, 400 usable data were employed here.

The questionnaire was designed and distributed through online channels and offline paper formats. 400 questionnaires were collected by sharing Google Form links to social platforms including Facebook, Line, and WeChat, and all respondents Chinese tourists (those living outside tourism destinations) visited and experienced selected tourism destinations, such as Bangkok, Kuala Lumpur, and Japan. Finally, the researchers received 400 complete questionnaires back from the online channel. All 400 paper questionnaires were completed.

The 30 pre-test questionnaires were collected in July 2021, and the actual 400 questionnaires were gathered in August 2021.

The six key constructs are four first-order latent constructs including the culture, architecture, transportation, and food of tourist destinations; and two second-order latent constructs composing of Emotional and Physical factors as shown in the conceptual model. Multi-item scales were adapted from those used in previous empirical studies. All items were measured on five-point Likert-type scales ranging from one "strongly disagree" to five "strongly agree".

The second-order factor structural equation modeling was used to analyze data since it is the most feasible approach to represent such a hierarchical structure, implying the association between a second-order factor (Emotional and Physical factors) and measured variables (manifest items surveys including destination culture, architecture, transportation, and food) could be mediated by the first-order factors.

In addition to the second-order SEM analysis, we also apply Multinomial Logistic Regression to examine the comparative advantages of each destination from the perspective of Chinese tourists. Also, we use cross-tabulation analysis to get a closer understanding of Chinese tourist's profiles on each destination, which has some managerial implications for the tourist authority of the countries studied.

\section{Results}

The second-order SEM results shown below indicate that our proposed model fitted well according to the descriptive measures: i.e., RMSEA was $0.03(<0.06)$ and the values of GFI, AGFI, NFI, TLI, and CFI were greater than 0.9 (most of which were larger than 0.95). More importantly, Food (F), Emotional Factor (EF) representing food and cultural indulgence, and Physical Factor (PF) indicating Architecture and Transportation facility of the destination had significant effects on tourist destination choice due to their p-values of less than 0.05. It implies that we can reject the null hypothesis of $\mathrm{H} 4, \mathrm{H} 5$, and $\mathrm{H} 6$ and accept their corresponding alternative hypotheses. Hence, this study concluded that Thai food and anything that could maximize the emotional and functional values of Chinese tourists would make travel choices and become their travel destination. 
Table 1. SEM output

\begin{tabular}{lllll}
\hline Model & RMR & GFI & AGFI & PGFI \\
\hline Default model & .032 & .937 & .922 & .750 \\
Saturated model & .000 & 1.000 & & \\
Independence model & .889 & .104 & .022 & .095 \\
\hline
\end{tabular}

Table 2. Baseline comparisons

\begin{tabular}{llllll}
\hline Model & $\begin{array}{l}\text { NFI } \\
\text { Delta1 }\end{array}$ & $\begin{array}{l}\text { RFI } \\
\text { rho1 }\end{array}$ & $\begin{array}{l}\text { IFI } \\
\text { Delta2 }\end{array}$ & $\begin{array}{l}\text { TLI } \\
\text { rho2 }\end{array}$ & CFI \\
\hline Default model & .963 & .957 & .990 & .988 & .990 \\
Saturated model & 1.000 & & 1.000 & & 1.000 \\
Independence model & .000 & .000 & .000 & .000 & .000 \\
\hline
\end{tabular}

Table 3. RMSEA

\begin{tabular}{|c|c|c|c|c|c|c|c|}
\hline \multicolumn{3}{|l|}{ Model } & RMSEA & \multicolumn{2}{|c|}{ LO 90} & HI 90 & PCLOSE \\
\hline \multicolumn{3}{|c|}{ Default model } & .030 & \multicolumn{2}{|c|}{.021} & .038 & 1.000 \\
\hline \multicolumn{3}{|c|}{ Independence model } & .278 & \multicolumn{2}{|c|}{.273} & .283 & .000 \\
\hline & & & Estimate & S.E. & C.R. & $\mathrm{P}$ & Label \\
\hline B & $<---$ & $\mathrm{F}$ & .871 & .200 & 4.350 & $* * *$ & \\
\hline B & $<---$ & $\mathrm{EF}$ & -.595 & .131 & -4.549 & $* * *$ & \\
\hline B & $<---$ & $\mathrm{PF}$ & -.866 & .081 & -10.737 & $* * *$ & \\
\hline
\end{tabular}

The detailed standardized parameter estimates are shown below:

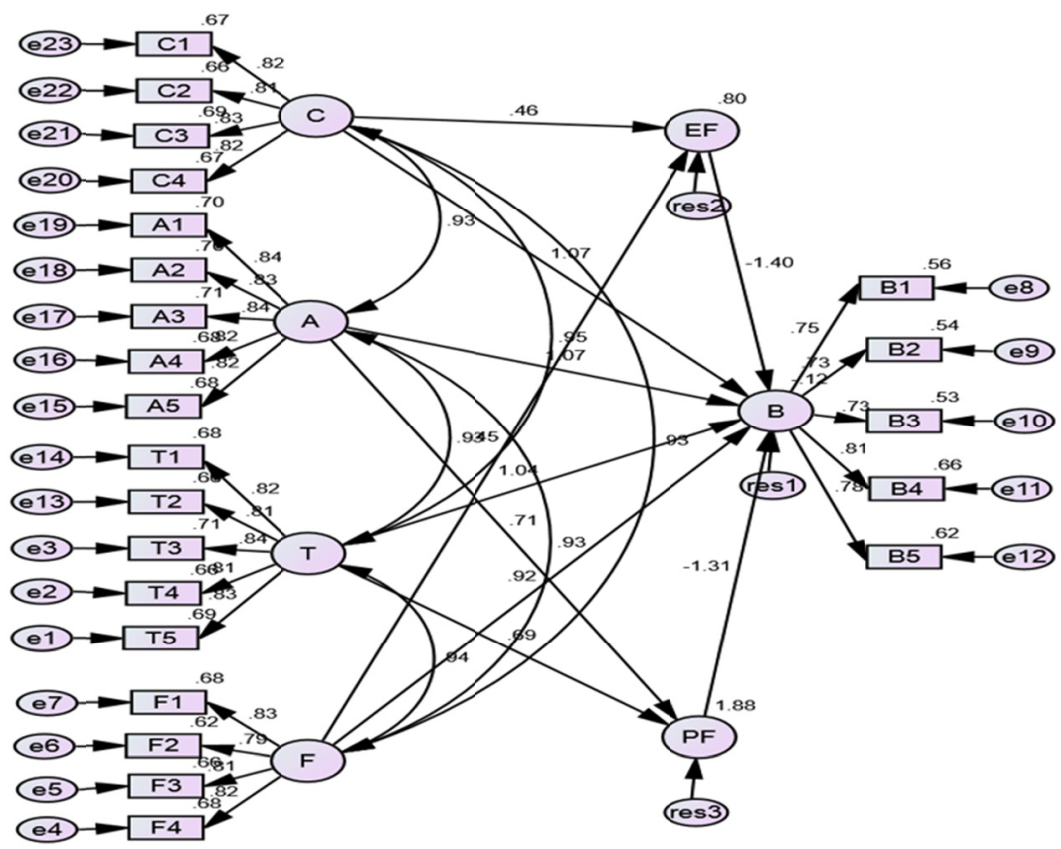

Figure 2. SEM model

As shown below, Multinomial Logistic Regression's result shows that Bangkok and Kuala Lumper had significantly more cultural attraction to Chinese tourists than to Japan. Moreover, Kuala Lumper's architecture was also significantly more attractive to Chinese tourists in comparison with the Japanese. 
Table 4. Model fitting information

\begin{tabular}{lllll}
\hline Model & Model Fitting Criteria & Likelihood Ratio Tests & \\
\hline & -2 Log Likelihood & Chi-Square & df & sig \\
\hline Null & 687.286 & & & \\
Final & 611.903 & 75.384 & 50 & .012 \\
\hline
\end{tabular}

Table 5. Parameter estimates

\begin{tabular}{|c|c|c|c|c|c|c|c|c|c|}
\hline \multirow{2}{*}{\multicolumn{2}{|c|}{$\begin{array}{l}\text { Which tourist destination is your } \\
\text { preferred one? }\end{array}$}} & \multirow[t]{3}{*}{ B } & \multirow[t]{3}{*}{ Std.Error } & \multirow[t]{3}{*}{ Wald } & \multirow[t]{3}{*}{ df } & \multirow[t]{3}{*}{ Sig. } & \multirow[t]{3}{*}{$\operatorname{Exp}(B)$} & \multicolumn{2}{|c|}{$\begin{array}{l}95 \% \text { Confidence Interval for } \\
\operatorname{Exp(B)}\end{array}$} \\
\hline & & & & & & & & Lower & Upper \\
\hline & & & & & & & & Bound & Bound \\
\hline Bangkok & Culture & 1.142 & 0.512 & 4.98 & 1 & 0.026 & 3.132 & 1.149 & 8.538 \\
\hline Kuala & Culture & 0.965 & 0.476 & 4.113 & 1 & 0.043 & 2.625 & 1.033 & 6.669 \\
\hline Lumpur & Architect & -0.845 & 0.43 & 3.87 & 1 & 0.049 & 0.43 & 0.185 & 0.997 \\
\hline
\end{tabular}

${ }^{\mathrm{a}}$ The reference category is: Japan.

The study of tourist profiles for each destination found the followings: First, female tourist tends to prefer Bangkok over KL and Japan. Second, Younger Chinese tourists prefer Bangkok over KL and Japan, while older one prefer KL more than Bangkok and Japan respectively. Third, Single Chinese tourist definitely prefers Bangkok over KL and Japan, while married couples equally prefer Bangkok and KL more than Japan.

\section{Conclusion}

This study aims to expand the scope and level of commonly used constructs influencing tourist destination such as behavioral intentions, namely, destination image, motivation, perceived quality, and WOM used by Mohaidin, Wei and Ali Murshid (2017); attraction, accessibility, accommodation, amenity, and activities proposed by Monsur Ahmed, Sakchai Setarnawat and Petcharut Viriyasuebphong (2020); price (costs of travel and stay in the destination and attraction sites), uniqueness of the attraction site features by BRIAN B. FRED (2015), etc. Each tourist destination has its own special set of attractions especially those destinations belonging to the same consideration from the perspective of tourists. That resulted in that we incorporate some factors that should be specific to the selected competitive set of destinations for Chinese tourist's consideration. That included the culture, architecture, transportation, and food of the destination. Thus, there should be deeper factors than easily observe making tourists fall in love with their preferred destination choice. It led to the fact that we characterized our model structure as a second-order latent construct and incorporate second-order latent factors as Emotional and Physical factors to capture some unforeseen and unobservable variables. These require future studies to include some new variables that might affect tourist emotional and/or functional perception.

Current destinations face the fiercest competition in decades, and the situation will only get worse over the next few years. Therefore, destination marketers need to better understand the reasons for travelers' loyalty to destinations and the factors that determine passenger loyalty. This research provides important implications for loyal tourists to their destination.

\section{References}

Augustyn, M., \& Ho, S. K. (1998). Service quality and tourism. Journal of Travel Research, 37(1), 71-75. https://doi.org/10.1177/004728759803700110

Bonn, M. A., Joseph-Mathews, S. M., Dai, M., Hayes, S., \& Cave, J. (2007). Heritage/cultural attraction atmospherics: Creating the right environment for the heritage/cultural visitor. Journal of Travel Research, 45(3), 345-354. https://doi.org/10.1177/0047287506295947

Brian, B. F. (2015). The factors influencing the choice of tourist Destatinations and attraction sites among international tourists - the case study of the northern tourist circuit - Arusha and Kilimanjaro regions.

Chandralal, L., \& Valenzuela, F. R. (2015). Memorable tourism experiences: Scale development. Contemporary Management Research, 11(3), 291-310. https://doi.org/10.7903/cmr.13822

Chen, J. S., \& Gursoy, D. (2001). An investigation of tourists' destination loyalty and preferences. International $\begin{array}{llllll}\text { Journal of Contemporary } & \text { Hospitality } & \text { Management, } & 13(2), & 79-85 . \\ \text { https://doi.org/10.1108/09596110110381870 }\end{array}$

Chen, K.-H., Chang, Y.-W., \& Lin, S.-J. (2013). The study of food and beverage arrangement in package tourists: 
A case of inbound tourists in Taiwan (pp. 463-486). Proceedings of 2013 International Conference in Chinese Food Culture.

Crompton, J. L., Lee, S., \& Shuster, T. J. (2001), A guide for undertaking economic impact studies: The $\begin{array}{lllll}\text { Springfest example. Journal of Travel Research, 40(1), 79-87. } & \text {. }\end{array}$ https://doi.org/10.1177/004728750104000110

Gelbman, A., \& Timothy, D. J. (2011). Border complexity, tourism and international exclaves: A case study. Annals of Tourism Research, 38(1), 110-131. https://doi.org/10.1016/j.annals.2010.06.002

Heung, V. C. S., \& Quf, H. (2000). Hong Kong as a Travel Destination: An Analysis of Japanese Tourists' Satisfaction Levels, and the Likelihood of Them Recommending Hong Kong to Others. Journal of Travel \& Tourism Marketing, 9(1-2), 57-80. https://doi.org/10.1300/J073v09n01_04

Jun, W., Metin, K., Shaohua, Y., Fang, L. et al. (2021). COVID-19: Potential effects on Chinese citizens' lifestyle and travel. Tourism Review, 76(1), 74-87. https://doi.org/10.1108/TR-03-2020-0110

Kato, K. (2018). Debating sustainability in tourism development: Resilience, traditional knowledge and community: A post-disaster perspective. Tourism Planning \& Development, 15(1), 55-67. https://doi.org/10.1080/21568316.2017.1312508

Mohaidin, Z., Wei, K. T., \& Ali Murshid, M. (2017). Factors influencing the tourists' intention to select sustainable tourism destination: A case study of Penang, Malaysia. International Journal of Tourism Cities, 3(4), 442-465. https://doi.org/10.1108/IJTC-11-2016-0049

Mohammad, S. M., Foroudi, P., \& Tabaeeian, R. A. (2021). Memorable experience, tourist-destination identification and destination love. International Journal of Tourism Cities, Vol. ahead-of-print No. ahead-of-print. https://doi.org/10.1108/IJTC-09-2020-0176

Monsur, A., Sakchai, S., \& Petcharut, V. (2020). The Factors Affecting Tourist Decision Making to Bangladesh as the Leisure Destination: A Case Study of Cox's Bazar Sea Beach. Faculty of Management and Tourism, $17(2), 2562$.

Rowley, J. (2014). Designing and using research questionnaires. Management Research Review, 37(3), 308-330. https://doi.org/10.1108/MRR-02-2013-0027

Tak, K. H., David, W., \& Alvin, H. (2007). Tourists' satisfaction, recommendation and revisiting Singapore. Tourism Management, 28(4), 965-975. https://doi.org/10.1016/j.tourman.2006.08.008

Tsai, C., Wu, T., Wall, G., \& Linliu, S. (2016). Perceptions of tourism impacts and community resilience to natural disasters. Tourism Geographies, 18(2), 152-173. https://doi.org/10.1080/14616688.2016.1149875

\section{Copyrights}

Copyright for this article is retained by the author, with first publication rights granted to the journal.

This is an open-access article distributed under the terms and conditions of the Creative Commons Attribution license (http://creativecommons.org/licenses/by/4.0/). 